\title{
The unidirectional relationship between consumer confidence and PSI-20 returns - The influence of the economic cycle ${ }^{\star}{ }^{\star}$
}

\author{
Maria Elisabete Duarte Neves \\ Instituto Superior de Contabilidade e Administração de Coimbra, Departamento de Finanças, Coimbra, Portugal
}

Luís Miguel Aragão Duarte Gonçalves

Banco BIC Português.S. A., Direção Regional Castelo Branco, Coimbra, Portugal

Mario Joaquim Silva Ribeiro

Banco Santander Totta, Coimbra, Portugal

Paulo Jorge Santiago Feiteira

Garval-SGM, Coimbra, Portugal

Clara Margarida Pisco Viseu

Instituto Superior de Contabilidade e Administração de Coimbra, Departamento de Matemática e Informática, Coimbra, Portugal

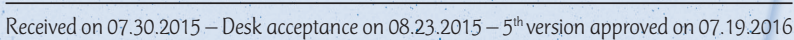

\section{ABSTRACT}

The aim of this paper is to determine the relationship between market sentiment and rates of return on the main Portuguese benchmark and verify whether this relationship is influenced by different economic cycles. Given the subjectivity inherent to the use of variables capturing investor sentiment, the Consumer Confidence Index (CCI) was used as a benchmark. To achieve the proposed objective, an analysis of time series stationarity, Pearson correlation, and Granger causality using the autoregressive vectors model was carried out, followed by the Least Squares Method with macroeconomic variables. The results obtained suggest a one-way relationship between stock market returns and the sentiment variable. In fact, in times of recession, investor pessimism induces linear behavior and the sentiment-return relationship is more evident. This article will thus be of interest both to the academic community, in providing a basis for future investigations, and to managers and investors, with regards to the perception that the predictability of returns will be easier in periods of recession.

Keywords: financial markets, behavioral finance, Consumer Confidence Index, PSI-20, economic cycle. 


\section{INTRODUCTION}

Contrary to the arguments of Traditional Finance, investors are not completely rational in their investment decisions (Baker, Ruback, \& Wurgler, 2004), which is a reality that has been studied in detail in recent decades by so-called Behavioral Finance. One of the main themes addressed by this theory is the effect of sentiment in investment decision making (Hirshleifer, 2001; Malmendier \& Geoffrey, 2005).

Shiller (2005) argued that cognitive dissonance plays a fundamental role in investor decisions and that the inclusion of knowledge from areas such a psychology should not be overlooked. According to the author, the effect of positive and negative information tends to quickly create a multiplying process in the market via "herd" behavior. Within this topic, Schmeling (2009) analyzed the relationship between sentiment and returns in countries with different cultures and concluded that, in those with a greater tendency for herding, investors were subject to the sentiment-return relationship. Similarly, Blasco, Corredor, and Ferreruela (2012), in a study based on a market with characteristics similar to those of Portugal and with proximity to a border - the Spanish market - herd behavior among investors was explored. The main aim of these authors was to determine rational and emotional factors and identify the relationships between them. They reached the conclusion that there is herd behavior in that market and that the intensity of this behavior depends on previous returns, confirming the existence of rational and emotional factors. It is also important to highlight that the individual investor can be susceptible to exerting influence on shares prices due to some irrationality and beliefs in expectations of returns, the so-called noise traders. Barber, Odean, and Zhu (2009) documented significant herd behavior in individual investors. In this paper, they demonstrated that psychological bias probably contributes to individual's trading in a highly correlated way, leading investors to systematically buy shares with better recent performance. On the other hand, Serapio, Barbedo, and Araújo (2015) analyzed the herd effect in the Brazilian stock market, demonstrating that in 30 minutes there is no significant effect. However, they suggested the existence of the same effect via intraday evaluation.

The basic assumptions of behavioral finance theory argue that the investor has non-rational feelings and emotions that can affect the price of securities. Shu (2010), for example, empirically demonstrated that investor mood influences share prices. Papavassiliou (2014), in his study of Greece, which like Portugal received international assistance following the public debt crisis, demonstrated that the prices of stocks and bonds fall during periods of turbulence.

The importance of sentiment in financial markets can also be recognized in the paper offered by Zouaoui, Nouyrigat, and Beer (2011), which demonstrated that the impact of sentiment on investors in stock markets is more pronounced in countries that are culturally more prone to herd behavior, overreaction, and little institutional involvement. Similarly, Bathia and Bredin (2013) studied the relationship between investor sentiment and market returns on shares in the G7. Using a series of proxies to identify investor sentiment between 1995 and 2007, they demonstrated a negative relationship between investor sentiment and future returns.

With relation to the introduction of the effect in different economic cycles, Chung, Hung, and Yeh (2012), in examining the predictive power of investor sentiment for returns on shares in recessionary and expansionary phases (in accordance with National Bureau of Economic Research business cycles), demonstrated that, during recessionary periods, the predictive power of investor sentiment is generally insignificant. Brown and Cliff (2005), using survey data on investor sentiment from Investor's Intelligence (which controls the number of bull, bear, and neutral market reports), demonstrated that sentiment is affected by share prices and that the market becomes overvalued during periods of optimism. Kurov (2010) demonstrated that the effect of news on sentiment depends on whether market conditions are bull or bear. This author also identified that monetary policy during bear market periods can have a greater effect on shares, which are more sensitive to changes in investor sentiment and to credit market conditions. Similarly, Lopez-Salido, Stein, and Zakraj`sek (2015) emphasized the importance of credit market sentiment and their results suggest that variations in expected returns for credit market investors may be an important driver of economic fluctuations, i.e. a key factor in the business cycle. Bernanke, Gertler, and Gilchrist (1999), or Kiyotaki and Moore (1997) can be cited as classics in the investigation of the role of financial markets in business cycle fluctuations. Similarly, Chordia and Kumar (2002) published an interesting article on the influence of momentum strategy during expansionary periods.

In a recent study linking the sentiment effect with economic cycles, Garcia (2013) analyzed the effect of sentiment via news agencies during periods of recession. This article, for the US market, aimed to study the effect of investor sentiment on share values between 1905 and 2005. According to the author, this was the first study that demonstrated that sentiment can be predictive of the behavior of returns on shares, especially during recessionary economic cycles. The proxy for sentiment used by this author was constructed using the number of positive and negative words in two columns of the New York Times published daily between 1905 and 2005. The results indicated that the content of 
news has a more pronounced effect on Dow Jones Industrial Average returns during recessions.

With regards to the main theoretical lines, in this article, firstly we present the article from Garcia (2013), the aim of which is very similar to our own; and secondly, the paper from Fernandes, Gama, and Vieira (2013), since they used Portugal for their sample and as a proxy for sentiment, one of the variables we intend to analyze: the Consumer Confidence Index (CCI). Fernandes et al. (2013) used the Economic Sentiment Indicator and the CCI as proxies for investor sentiment, aiming to identify whether these variables predicted future returns on the global equities market and returns on industrial indices in Portugal, between September 1997 and April 2009. Similarly, they verified whether the relationship between sentiment and expected returns was significantly negative, even after controlling for macroeconomic factors. They used a system of equations to verify the existence of this effect for one, three, six, and 12 months, concluding that sentiment has a negative impact on future market returns for one to 12 month forecasts (consistent with so-called noise trader behavior).

In this context, the aim of this paper was to empirically test the existence of the non-rational effect on returns in the main Portuguese index, the PSI-20. Moreover, we aimed to verify whether this relationship is influenced by different economic cycles. To achieve this objective, complete data on the Portuguese market regarding the previous decade from
2003 to 2013 were collected. Given the absence of data on investor sentiments and emotions, unlike in the US market, we considered the CCI as our study variable, since there are no data published in the country, in newspapers and/or in any other means of communication, regarding investor sentiments and emotions. This alteration implies certain advantages, especially due to the fact that a quantitative variable is concerned which can be easily handled and compared. Baker and Wurgler (2006) claimed that "there are no undisputed or definitive measures of investor sentiment" (p. 1655).

This paper, using an original approach, establishes the link between sentiment and returns in the Portuguese market, influenced by the economic cycle over a decade. Our results, using linear regression after considering the "stationarity" of the data, demonstrate that there is a relationship between returns and sentiment and that this effect is more intense during recessionary periods.

This article is divided in the following way: Section 2 presents the theoretical framework regarding the existing literature and the empirical evidence on the influence of sentiment on share returns, including the effect of the economic cycle, and the hypotheses to be contrasted will be raised. In Section 3, the methodology used in the analysis is described. In Section 4 the results obtained are discussed and in Section 5 the conclusions are presented.

\section{THEORIES AND HYPOTHESES}

In this section, the most relevant contributions from the previous literature regarding the influence of sentiment on share returns will be presented, as well as how this relationship can be affected by different economic cycles.

Some authors, such as Hansen and Jagannathan (1997) and Hansen and Richard (1987), initiated the discussion on the paradigm of asset prices, and later, Cochrane (2005, 2011) based his papers on the concept of the stochastic discount factor.

Thaler (1999) claimed that understanding of financial markets is strengthened by the introduction of the human element, into which the study of investor sentiment can be inserted. Mishkin (2001) argued that investor expectations are not always totally rational with regard to asset prices in the capital market due to two fundamental reasons: the effort to find all of the information, despite this possibly being totally available, and the fact that investors are not aware of all of the information available. Daniel, Hirshleifer, and Subrahmanyam (1998) demonstrated that one sequence of good (or bad) news related with the economy leads companies to overvaluation (or undervaluation). Neal and Wheatley (1998) demonstrated, using two measures of individual investor sentiment, that sentiment foresees returns. Shefrin $(2005,2008)$ argued that asset prices reflect investor intervention. Shefrin (2005) introduced the concept of behavioral adjusted present values to which he added, to adjusted present value, a component that acquires the effects of an inefficient market. In these articles, Shefrin (2001, 2005) focused on so-called behavioral corporate finance and argued that, as well as conflicts of agency and information asymmetry, there are behavioral costs that can be obstacles in the value maximizing process.

For Baker and Wurgler (2007), investor sentiment represents a belief regarding future cash flows and cannot be justified by economic and financial information. These authors also emphasized the fact that investor sentiment is difficult to measure due to it concerning a subjective variable. Akhtar, Faff, Oliver, and Subrahmanyam (2012) documented the effects of the monthly consumer sentiment index and the negative effect that it can cause on US shares and in the futures market, especially when the index is positive.

It is important to highlight that, just as some authors conclude that sentiment can influence returns, others demonstrate that the link can be bilateral. Otoo (1999), for example, verified the existence of a strong relationship between variations in consumer confidence and share returns 
in the United States of America (USA) and concluded that shares prices influence consumer sentiment, but that the opposite is not verified. Fisher and Statman (2000) found that the causality between share returns and sentiment can be significant in both directions. Brown and Cliff (2004) used a great number of sentiment indicators to investigate the relationship between sentiment and returns and suggested evidences that sentiment is caused by returns.

Wang, Keswani, and Taylor (2006) demonstrated, empirically, that the sentiment measures used in their study are instigated by returns and volatility, and not the opposite.

In accordance with the arguments presented, we propose our first hypothesis:

Hypothesis 1: Sentiment Affects and/or is Affected by the Evolution of Stock Market Returns.

Otoo (1999) verified the existence of a strong relationship between variations in consumer confidence and returns on shares in the USA. This author considered that shocks in consumer sentiment do not have an impact on share prices.

Jansen and Nahuis (2003) elaborated a study in which they broke down the confidence index and concluded that economic agents can use share prices as an indicator of economic activity. They also indicated that high levels of returns boost consumer confidence.

Fisher and Statman (2003) verified the positive relationship between variations in consumer confidence and share returns. The greater returns are, the higher consumer confidence is. On the other hand, Charoenrook (2005) found evidence that investors become more optimistic and less risk averse, indicating that an increase in consumer sentiment can foresee lower returns. Schmeling (2009) corroborated that, when sentiment is rising, future returns on shares tend to be lower, and vice-versa. He also found empirical evidence in the fact that the impact of sentiment on share returns is greater in countries with less "integrity" and characterized by a "herd" culture and one of overreaction.
Lemmon and Portniaguina (2006) verified that most macroeconomic variables exhibit a contemporary correlation with consumer confidence. They thus concluded that consumer confidence can indicate returns on shares.

DeStefan (2004), in a paper that related share returns with the US market economic cycle, demonstrated that returns vary inversely with economic conditions, suggesting that gained returns are weak indicators for explaining expected returns before turning points in the economic cycle.

Leger and Leone (2007) observed systematic alterations in the structure of risk and assumed that consumer confidence captures a change in market sentiment, which may be an evolution in share prices.

Tetlock (2007) studied the influence of negative words on share returns via analysis of a daily column in the Wall Street Journal. This author demonstrated that for high levels of pessimism there is downward pressure on market prices, followed by a reversal to the fundamentals; however, for lower levels of pessimism, he predicted high volumes of market trading.

Garcia (2013) uses a proxy for sentiment constructed using the number of positive and negative words in two columns of the New York Times for the twentieth century and introduced the economic cycle factor to estimate the effect of reported content on returns on shares during recessionary and expansionary cycles. The results indicated that news content has a more pronounced effect on Dow Jones Industrial Average returns during recessions, particularly in the first four days after their publication. This effect is more pronounced on Mondays or after holidays, since investors have more time to read news published over weekends.

In accordance with the studies presented, we lay out the second hypothesis with the aim of verifying whether the economic cycle influences the sentiment-return relationship.

Hypothesis 2: Sentiment is Dependent on the Economic Cycle.

\section{METHODOLOGY}

\subsection{Data and Variables}

\subsubsection{PSI-20 data.}

\subsubsection{The importance of and justification for the study sample.}

Our study uses the PSI-20, the Portuguese market benchmark, for its sample. We aimed to study a small open economy (Euro Zone) in which shocks to the international economy play an important role. In times of financial and public debt crises and those involving a lack of confidence in the markets, Portugal has been the target, in recent years, of much internal and external criticism, justifying a deeper knowledge of this market. If the financial crisis that began in 2008 had drastic consequences for Portugal, the public debt crisis intensified and provoked more discomfort in relation to investment and returns in this market. The announcement of public investment plans, injections of capital into weakened financial institutions, and even nationalization of some of these institutions as a fallback solution made the country vulnerable in the European and global context. Also, with relation to the stock exchange, the main bourses in the world record a tendency for growth beginning in 2009 and 
continuing over 2010 - surpassing pre-crisis levels - notably in the performance of the German DAX-30 index, the US Dow Jones index, and the British FTSE 100 index, which increased 14\%, 9\%, and 9\%, respectively. The Portuguese stock market, on the other hand, with its benchmark index accumulating losses of $10.34 \%$ a year, reflects the negative effects of the public debt crisis. The beginning of 2010 seemed promising, with the PSI-20 recording a peak at the beginning of January; however, the values recorded at the end of the period revealed that this was a negative year for investors, with 15 companies from the main NYSE Euronext Lisbon index closing the year in negative territory and only five companies making gains. Thus, investigation of the topic seems appropriate, given the global interest that this country clearly presents, especially since the intervention of the European Commission, the European Central Bank (ECB), and the International Monetary Fund (IMF) in evaluating Portugal's real accounts.

The PSI-20 is the reference for various papers related to the Portuguese reality and is composed of the 20 largest companies traded in Portugal with regards to size and liquidity.

Our data refer to the period between the beginning of January 2003 and the end of December 2013, the last decade with complete data for which we had access. The data was collected using the Euronext website on May 11, 2014.

It is important to mention that, for the initial values related to this index, we used the closing values from each session, which lacked transformation for our model, as we will address over the course of the paper.

\subsubsection{Variables.}

\subsubsection{Dependent variable - CCI.}

Measures of sentiment can be classified as explicit measures, when the sentiment indicator is derived directly from investor surveys, and implicit measures, when the indicator is obtained based on indirect proxies (Fernandes et al. 2013). To test the hypotheses proposed we used, as a measure of sentiment, consumer confidence indicators in order to capture investor optimism or pessimism, as in the studies from Jansen and Nahuis (2003), Lemmon and
Portniaguina (2006), Otoo (1999), Schmeling (2009), and Zouaoui et al. (2011), among others. Fernandes et al. (2013) used the same index applied to the Portuguese market. It is worth highlighting that, as mentioned by Fuhrer (1993), when consumers are confident, the economy is stimulated, and when they are uncertain, the economy contracts, with it being necessary to find a tangible value for confidence. Similarly, Oest and Franses (2008) mention that confidence indicators reflect the present and help to attempt to verify an economy's future.

Thus, we start by addressing the CCI, which will be analyzed statistically and correlated with other macroeconomic variables from the same time scale.

Since there is no simple index in Portugal that can be used as a measure of sentiment, nor are there published studies of relevance and seniority regarding those measures used to analyze the US market by Tetlock (2007) or Garcia (2013), we aim, using other means, to break down an index in order to find our sentiment variable. This index is harmonized for various countries of the European Union and is used by the Director General - European Economic Financial Affairs and by the Portuguese National Institute for Statistics. A monthly-based index is concerned, based on 2,100 surveys (in Portugal), created in the first two weeks of each month. Citing Mendicino and Punzi (2013),

the consumer survey collects information on families' saving and consumption intentions and also evaluates their perception of the general economic and financial situation. The survey is conceived around four topics: families' financial situation, economic situation in general, savings, and major purchases. Around 2,100 consumers are surveyed every month in Portugal. The industry survey, in turn, concerns an evaluation of recent trends in production, orders, and stocks, and expectations regarding production, sales prices, and employment in the different sectors (p. 44)

For more details regarding the variables to be included in these surveys, the paper from Mendicino and Punzi (2013) is recommended. The result can vary between values of -100 and 100, in function of the equation below: 
The replies from those surveyed who answered "don't know" or "stayed the same" are not included.

The data gathered is based on the period between 2003 and 2013 using the Eurostat webpage on May 3, 2014.

\subsubsection{Independent variables.}

Our sentiment index was constructed based on CCI data, with it being necessary to include in our database a broad reference to macroeconomic variables. Table 1 indicates the variables and respective data sources.

Table 1 Variables and source of data

\begin{tabular}{cc}
\hline Variables & Source \\
\hline Macroeconomic variables & Eurostat (April 17, 2014) \\
\hline Variation in real GDP & NIS (April 17, 2014) \\
\hline Private consumption & NIS (May 11, 2014) \\
\hline Rate of unemployment & NIS (April 18, 2014) \\
\hline Rate of inflation & Quandl (April 18, 2014) \\
\hline Euribor (3 months) & Eurostat (May 11, 2014) \\
\hline TBs and Portuguese TBs (10 years) & \\
\hline PSI-20 Data & Euronext (May 11, 2014) \\
\hline Returns on PSI-20
\end{tabular}

Note. $G D P=$ Gross domestic product; NIS = National Institute of Statistics; TBs = Treasury Bonds.

Source: Elaborated by the authors.

\subsection{Analysis Procedures}

\subsubsection{Stationarity of logarithmic returns on PSI-20.}

With our handling of the data we intend to understand what is the relationship between sentiment and return and whether or not this is independent of the economic cycle. This last intention was never addressed in any paper produced regarding the Portuguese reality, which makes our work original and contemporary. The long and recent period analyzed allows differences to be observed in recessionary and expansionary periods, and at the same time, because it is current, levels of social and technological evolution can be considered in the conclusions.

In order to achieve this objective, we started by analyzing the data regarding PSI-20 returns. Based on the data from the close of each session we found the monthly arithmetical average used as a base for analyzing the stationarity of the series. Based on the monthly averages obtained, we used the calculation of monthly logarithmic returns, an approach that allowed us to standardize the data, which is essential for the intended statistical analysis.

Using the EViews 7.0 software allowed the time series analysis, as presented in Annex 1, proving, for a 5\% degree of significance, that the series is stationary. Analysis of the correlogram for the series, using the Ljung and Box test, allowed it to be concluded that up to the $26^{\text {th }}$ observation we have a $\mathrm{p}$ value lower than $5 \%$, leading us to conclude through rejection of the hypothesis that autocorrelation does not exist. We finished the analysis using a test to choose the most suitable true model, the Akaike test, and our best equation was thus estimated:

$$
r_{t}=0.001518+0.300181 r_{t-1}
$$

\subsubsection{Stationarity of the data related to the CCI.}

The data related to the CCI are provided on a monthly basis and are negative for all of the analysis period considered. Thus, it was necessary to work with standardized and dynamic data, since the intention was to analyze the behavior of the evolution of the index, and not its absolute results.

In order to only work with positive data, since the index varies between -100 and 100 , we added, to the monthly values collected, the value of 100 . This transformation would imply that the index could vary between 0 and 200, without there being any biasing effect for our analysis.

Thus, we started by calculating the arithmetical average for each quarter in the decade. Based on these values, to analyze the index dynamic in a standardized way, it was necessary to obtain the logarithmic variations in the index based on the previously calculated average quarterly data. Using the same biased method to analyze the stationarity of the logarithmic returns on the PSI-20, we analyzed the 
logarithmic variations in the CCI, and for a 5\% degree of significance, we concluded that the time series is stationary (Annex 2).
After this verification, we again used the Akaike test to determine our best model, given by the following equation:

$$
\mathrm{r}_{t}=0.001875+0.197203 r_{t-1}
$$

\subsubsection{Handling of the macroeconomic variables.}

All of the macroeconomic variables used were transformed so that they had the same quarterly base.

Thus, since one of the aims of this paper was to understand the impact that different economic cycles have on the sentiment-return relationship, it was necessary to identify each period in the analysis period. Thus, based on the European definition of recession, we considered recession as a period in which for three or more consecutive periods in which falls in real gross domestic product (GDP) are verified. We concluded, from the start, that in the analysis period it was possible to record three periods of recession (the first three quarters of 2003, the period between the $4^{\text {th }}$ quarter of 2008 and the $4^{\text {th }}$ quarter of 2009 , as well as the period between the $1^{\text {st }}$ quarter of 2011 and the $3^{\text {rd }}$ quarter of 2013). Three periods of expansion (between the $4^{\text {th }}$ quarter of 2003 and the $3^{\text {rd }}$ quarter of 2008 , all of 2010, and the last quarter of 2013) were recorded.

\subsection{Empirical model}

\subsubsection{Sentiment index determination.}

After standardizing the data, it was possible to estimate the sentiment index based on the CCI variations. In order to estimate our model we first used the analysis that was carried out previously with the Akaike model, which recommended the use of a one quarter time lag, leading us to the use of data from period $(\mathrm{t})$, but also from the previous quarter $(\mathrm{t}-1)$.

The estimation of this model is based on a linear regression model in which:

- The dependent variable considered is that from the transformed CCI;

- The independent variables in the initial regression model: the quarterly variation in GDP, the quarterly logarithmic variation in private consumption $\left(\mathrm{PC}_{\mathrm{t}}\right)$, the percentage variation in the rate of unemployment in each quarter (UNEMP), the quarterly variation in inflation (INF), the quarterly variation in the Euribor $\left(\mathrm{E} 3 \mathrm{M}_{\mathrm{t}}\right)$, and the quarterly variation in Portuguese Treasury Bonds (TBs) every ten years $\left(\mathrm{TB}_{\mathrm{t}}\right)$, in the secondary market. We also included the same GDP and private consumption variables related to period $\mathrm{t}-1$ due to them not being stationary.

Our base model is thus presented:

$$
C C I_{t}=a+\alpha \times G D P_{t}+\beta \times P C_{t}+\gamma \times U N E M P_{t}+\delta \times I N F_{t}+\zeta \times E 3 M_{t}+\eta \times T B_{t}+\theta \times G D P_{t-1}+\lambda \times P C_{t-1}+\rho C C I_{t-1}+\varepsilon
$$

After this approach, we obtained our linear regression model, which allowed us to estimate the expected CCI, which is determinant for measuring the sentiment index.
Adjusting the linear regression model only with the variables that are relevant to the model, it was possible to determine the following equation:

$$
\widehat{C C I}=4.98+1.83 G D P_{t}-2.05 G D P_{t-1}+0.92 C C I_{t-1}
$$

In order for us to determine the sentiment index we considered that the motivations that determine variations

$$
C C I=\text { rational motivations (macroeconomic data) + non-rational motivations (sentimental) }
$$

This proposal allowed us to conclude that the sentiment index in each period will be given by the residual that is not explained by rational means, that is, by the difference between the value observed for the CCI and the expected value using the linear regression model which incorporates the rational aspect. 
3.3.2 Statistical analysis for the whole period (20032013).

After determining the sentiment index necessary for our analysis, it was necessary to standardize the logarithmic returns on the PSI-20. The calculated return was based on the logarithmic difference between the values for $t$ and $t-1$.

After this process, the following were considered for the linear regression model:

- Dependent variable: logarithmic returns between quarters;

- Independent variable: sentiment index (quarterly difference between observed CCI and estimated CCI).

In a first approach we can conclude that the sentiment index allows around $18 \%$ of the evolution in quarterly logarithmic returns to be explained.

Since one of the aims of this paper is to verify whether returns on the PSI-20 affect and/or are affected by the sentiment effect, we used the Granger test to determine whether the variables are independent, interdependent, or whether there is dependency, but only in one direction, between the variables.

In this test, from the start we used the time difference of only one quarter (lag1), which allowed us to conclude that sentiment does not directly affect logarithmic return on the PSI-20, but rather is influenced by this. The unilateral relationship between the variables is thus established (Annex 3).

After this analysis, we aimed to verify whether the effect that returns on the PSI-20 caused on sentiment had a merely short term effect or whether, on the other hand, it remained over time. We carried out the same analysis mentioned earlier, but using a difference of up to one year (lag4). The results demonstrated that the effect of returns on the PSI20 on sentiment is diluted over time, and that, with a $5 \%$ degree of significance, we would have to conclude that the variables were independent for a one year lag. Due to the results obtained using the Granger method, in order to quantify the relationship between the variables, we redid our linear regression model, considering:

- Dependent variable: sentiment index (quarterly difference between observed CCI and estimated $\mathrm{CCI}$;

- Independent variable: logarithmic returns between quarters.

From the results obtained and discussed in Table 3 we can write the estimated model for all of the period considered:

$$
\text { Sentiment }=0.367604+45.09953 \times \text { return }
$$

It should be observed that this transformation does not imply any alteration in the value of the determination coefficient obtained, which allows it to be concluded that returns on the PSI-20 explain around 18\% of the evolution of the CCI.

\subsubsection{Statistical analysis for the expansionary periods.}

Just as we have mentioned, in order to analyze the existing differentiation in the relationship between return and sentiment for crisis periods and for expansionary periods, as a reference we took the data related to evolution in real GDP, which allowed us to conclude that there are three recessionary periods and three expansionary periods for the time interval analyzed.

Thus, we first isolated the expansionary periods in order to understand how the variables were related to each other, and above all, verify whether the effect of the relationship was identical to that which we concluded when we considered the whole period.

\subsubsection{Statistical analysis for the recessionary periods.}

The aim of this paper was to verify, as in Garcia (2013), the essential study in the development of our model, whether the effect of investor sentiment was concentrated in recessionary periods, and because of this, the analysis went on to isolate the values related to periods of economic recession, as we had already done for expansionary periods.

With the data handled in this way, we estimated the linear regression model for the recessionary periods in the sample, which we summarize in the following equation:

$$
\text { Sentiment }=0.443191+49.39723 \times \text { return }
$$

\section{RESULTS}

First, the results from the linear regression model, which includes the set of macroeconomic variables in the variation in the CCI, will be presented. The main results can be verified in Table 2. 
Table 2 Results from the regression model estimations

\begin{tabular}{|c|c|c|}
\hline & Model (4) & Model (5) \\
\hline Constant & $\begin{array}{r}5.414041 \\
(0.4846)\end{array}$ & $\begin{array}{l}4.98044 \\
(0.4427)\end{array}$ \\
\hline GDP & $\begin{array}{l}1.602275 \\
(0.0995)\end{array}$ & $\begin{array}{l}1.83177 \\
(0.0067)\end{array}$ \\
\hline $\operatorname{GDP}(-1)$ & $\begin{array}{c}-1.835849 \\
(0.0113)\end{array}$ & $\begin{array}{c}-2.053130 \\
(0.0014)\end{array}$ \\
\hline PC & $\begin{array}{c}-7.803843 \\
(0.7032)\end{array}$ & - \\
\hline PC $(-1)$ & $\begin{array}{c}-3.962725 \\
(0.8583)\end{array}$ & - \\
\hline UNEMP & $\begin{array}{c}-0.304108 \\
(0.8506)\end{array}$ & - \\
\hline E3M & $\begin{array}{l}1.571564 \\
(0.4534)\end{array}$ & - \\
\hline INF & $\begin{array}{c}-0.679223 \\
(0.5350)\end{array}$ & - \\
\hline TB & $\begin{array}{c}-0.576616 \\
(0.5051)\end{array}$ & - \\
\hline $\mathrm{CCl}(-1)$ & $\begin{array}{c}0.919158 \\
(0.0000)\end{array}$ & $\begin{array}{l}0.91651 \\
(0.0000)\end{array}$ \\
\hline R-squared & 0.863178 & - \\
\hline Adjusted R-squared & 0.825862 & - \\
\hline F statistic & 23.13205 & - \\
\hline Probability (F statistic) & 0.000000 & - \\
\hline
\end{tabular}

Note. $P C=$ private consumption; UNEMP = rate of unemployment; $E 3 M=$ quarterly variation in the Euribor; CCI =Consumer Confidence Index; INF = variation in inflation; $T B=$ Treasury Bonds; GDP = gross domestic product.

Source: Elaborated by the authors.

In the first column in Table 2, we concluded that the CCI variable lagged by one period, as well as the GDP variable lagged by 1 period, are statistically relevant for degrees of significance of $5 \%$ and $10 \%$ (the test values associated with individual significance are 0.0000 and 0.0113 , respectively). From the F statistic value (23.13205) we concluded that the independent variables are, together, statistically significant, influencing the dependent variable for a $5 \%$ degree of significance. The residuals from the model were analyzed having verified that they behave as white noise (the value of the Breusch-Godfrey serial correlation test is 0.64).

As can be observed in the second column in Table 2, model (5) is globally suitable (the value of the F statistic is 77.31434 and the test value is 0 ) and the independent variables are statistically significant for the usual degrees of significance $(1 \%, 5 \%$, and $10 \%)$. The determination coefficient indicates that $85.6 \%$ of the variation in CCI is explained by the variables present in the model. To validate the model, the residuals were analyzed, having verified that they behaved as white noise (the value of the BreuschGodfrey serial correlation test is 0.41 ).

With the aim of verifying the influence of PSI-20 returns and addressing the different economic cycles, Table 3 presents the results from the models defined in the previous section for the three periods: the whole period, expansion, and recession. 
Table 3 Results from the regression model estimations

\begin{tabular}{|c|c|c|c|}
\hline & $\begin{array}{l}\text { Whole } \\
\text { period }\end{array}$ & $\begin{array}{c}\text { Expansionary } \\
\text { period }\end{array}$ & $\begin{array}{c}\text { Recessionary } \\
\text { period }\end{array}$ \\
\hline Constant & $\begin{array}{c}0.36760 \\
(0.79690)\end{array}$ & $\begin{array}{c}0.51461 \\
(0.78870)\end{array}$ & $\begin{array}{c}0.44319 \\
(0.84960)\end{array}$ \\
\hline RET & $\begin{array}{c}46.699530 \\
(0.0050)\end{array}$ & $\begin{array}{c}27.773120 \\
(0.2341)\end{array}$ & $\begin{array}{c}49.397230 \\
(0.0209)\end{array}$ \\
\hline R-squared & 0.180809 & 0.060957 & 0.307422 \\
\hline Adjusted R-squared & 0.160330 & 0.020129 & 0.201250 \\
\hline F Statistic & 8.828683 & 1.493011 & 6.658212 \\
\hline Probability (F statistic) & 0.004998 & 0.234126 & 0.020900 \\
\hline
\end{tabular}

Note. $R E T=$ Return on PSI-20.

Source: Elaborated by the authors.

In Table 3 we can verify, for the whole period, that returns on the PSI-20 explain around $18 \%$ of the evolution of the CCI.

With the help of EViews we estimated a linear regression model with the data related to the times of expansion (second column, Table 3). For a 5\% degree of significance, we infer that there is no relationship between PSI-20 returns and evolution of the sentiment index. We found that the predictive ability of the model becomes residual (the value of the determination coefficient is 0.060957).

It is concluded that, at times of expansion, the influence caused by returns on the main Portuguese index do not have a significant impact on the perception of confidence, and consequently on sentiment.

With relation to the third column in Table 3, detailed analysis of the results obtained allows us to conclude that the predictive ability of the model increases to $30 \%$ and that, for a $5 \%$ degree of significance, the hypothesis that quarterly logarithmic returns on the PSI-20 influence the evolution of the sentiment index is accepted.

As in Blasco et al. (2012), who studied the Spanish market, our model suggests that there are factors that influence returns on the Portuguese market which are not explained by rational knowledge. Given the difficulties in finding complete data for long periods that are inherent to a small market like the Portuguese one, the result obtained seems interesting to us, unquestionably indicating that investors are not totally rational in their decisions.

In fact, from reading our results, the existence of a unilateral relationship showing that sentiment is affected by returns can be verified and the opposite is not verified. This result allows us to verify that the first hypothesis was corroborated. A similar result was obtained, for example, by Wang et al. (2006). Our empirical evidence also suggests that the effect of variations in market returns on shares on population sentiment is almost immediate, since it manifests itself in the period immediately after and does not persist permanently over time, with its effect being residual within the time frame of a year. This result is similar to that obtained by Jansen and Nahuis (2003).

With relation to hypothesis 2 , reading the data allows us to corroborate the proposed hypothesis, that is, sentiment depends on the economic cycle, with the division of the sample into recessionary and expansionary cycles being appropriate and having different results, as suggested in most of the literature presented, such as, for example, Chung et al. (2012) or Garcia (2013).

Finally, our results demonstrate, consistently with the conclusions of the study from Garcia (2013), that the relationship between returns and sentiment is more intense for recessionary periods. This author suggests that, in times of expansion, the rational aspect becomes more prevalent. Therefore, following Garcia (2013), our study demonstrated that the predictability of returns will be easier in recessionary periods.

Our results are also in agreement with those suggested by Kurov (2010), although his study was based on monetary policy, which showed that the effect of news on sentiment depends on whether market conditions are bull or bear, with monetary policy in bear market periods able to have a greater effect on shares that are more sensitive to changes in investor sentiment.

Using so-called behavioral finance as a foundation, some scientific papers have shown not totally rational behavior, especially in the face of potential loss at times of recession. Our study demonstrates exactly that Portuguese investors are not totally rational and are capable of adopting sentimental factors in their perceptions regarding the evolution of the economic and market reality as these economic cycles change. 
It is thus observed that the influence of sentiment in periods of crisis is more accentuated, which indicates that their decisions in these periods assume a less rational, probably more emotive component, in accordance with so-called herding behavior. Consistence can be noted with the results obtained in Neves, Proença, and Martins (2015), who demonstrated for the Portuguese market that shares are more correlated in periods of recession, reflecting the best effect of cohesion between companies with linear behavior, probably due to the more pessimistic reaction of investors.

Our paper focused on a specific reality, such as that for Portugal, and for a period of special integration of the economy into the European reality, with generalization of the conclusions referred to here lacking analysis compared to other realities using other variables and sentiment indices.

\section{CONCLUSIONS}

At the beginning of this investigation we proposed studying the relationship between the results observed in a small European market belonging to the Euro Zone and the decision component that is not justified by rational assumptions, in accordance with the economic cycle. The aim became to understand whether there is risk adverse behavior and a greater departure from the classic, rational explanation of investor decisions in periods of crisis.

In addressing the Portuguese reality, we found from the start that the differences compared to the US market, the most widely studied, are evident. The main Portuguese stock market index includes only 20 companies, with the spread between securities on the US market not being verified. If for the US analysis it is possible to analyze a period of 100 years based on information from news agencies, for Portugal the information available is restricted to recent decades and there is no journalistic column of reference able to efficiently reproduce information on investor sentiment. With the Portuguese stock market characteristics, our first challenge was to find an indicator that allowed for identifying, in an approximate way, investor sentiment, so that it was later possible to interpret the way it varied depending on the economic cycle. In the analysis carried out, one of the first conclusions indicates generalized pessimism among the Portuguese population, given that even when the macroeconomic indicators suggest an improvement in the economic situation, the index continues with negative values.

Throughout our analysis, in determining the sentiment component, it was possible to conclude that the non-rational component has a determinant influence on the evolution of the index.

Before incorporating the question of the economic cycle, it was important to verify whether the evolution of returns on shares was the cause or effect of sentiment. For this we used the Granger method, which led us to conclude that a unidirectional effect of returns on sentiment was concerned. It was therefore concluded that the existence of a variation in share returns can be understood as determinant for the economic expectations of the Portuguese. Even though only a small percentage of the population actually invests, the circulation of information has a determinant impact for the general understanding of the resulting economic effects. Finally, our results demonstrate that, in recessionary periods, the sentiment-return relationship is stronger, being almost insignificant in expansionary periods; therefore the predictability of returns will be easier in recessionary periods.

The limitations of this investigation are fundamentally related to defining a sentiment index as there is, for example, in the US reality, via Investor Intelligence. Also with relation to the difficulties found, it is important to stress that the frequency of data publication is not uniform, which implied an approximation approach regarding the observed values, using arithmetical averages that may lead to bias in the results.

For future investigations, we propose carrying out a comparative approach with other realities, namely that of other European countries, in order to allow for generalization of the results reached, especially in the Euro Zone. Similarly, as in Schmeling (2009) or Zouaoui et al. (2011), who demonstrated that the impact of sentiment on share returns is greater in countries more prone to a culture of herding and overreaction, it would be appropriate to verify the differences and/or similarities in the Euro Zone markets, separating those that experienced intervention by international institutions after the crisis.

The new paradigm will be to combine behavioral finance with the classic theory (De Bondt, Muradoglu \& Staikouras 2008) so that, in the future, the combination of asset price theory with behavioral assumptions and classic finance theories can be possible. 


\section{References}

Akhtar, S., Faff, R., Oliver, B., \& Subrahmanyam, A. (2012). Stock salience and the asymmetric market effect of consumer sentiment news. Journal of Banking and Finance, 36(12), 3289-3301.

Baker, M., \& Wurgler, J. (2006). Investor sentiment and the cross-section of stock returns, Journal of Finance, 61, 1645-1680.

Baker, M., \& Wurgler, J. (2007). Investor sentiment in the stock market. Journal of Economic Perspectives, 21, 129-15i.

Baker, M., Ruback, R., \& Wurgler, J. (2004). Behavioral corporate finance: a survey. The National Bureau of Economic Research. Retrieved from http://www.nber.org/papers/w10863.

Barber, B. M., Odean, T., \& Zhu, N. (2009). Systematic noise. Journal of Financial Markets, 12(4), 547-569.

Bathia, D., \& Bredin, D. (2013). An examination of investor sentiment effect on G7 stock market returns. The European Journal of Finance, 19(9), 909-937.

Bernanke, B., Gertler, M., \& Gilchrist, S. (1999). The financial accelerator in a quantitative business cycle framework. In J. B. Taylor, M. Woodford, Handbook of macroeconomics (pp. 1342-1393). NorthHolland, Amsterdam: EconPapers.

Blasco, N., Corredor, P., \& Ferreruela, S. (2012). Market sentiment: a key factor of investors' imitative behaviour. Accounting and Finance, 52(3), 663-689.

Brown, G., \& Cliff, M. (2004). Investor sentiment and near-term stock market. Journal of Empirical Finance, 11, 1-27.

Brown, G., \& Cliff, M. (2005). Investor sentiment and asset valuation. Journal of Business, 78(2), 405-440.

Charoenrook, A. (2005). Does sentiment matter?, unpublished manuscript. The Owen Graduate School of Management, Vanderbilt University. Retrieved from http://apps.olin.wustl.edu/ workingpapers/pdf/2008-12-003.pdf.

Chordia, T., \& Kumar, S. L. (2002). Momentum, business cycle, and time - varying expected returns. Journal of Finance, 57(2), 985-1019.

Chung, S. L., Hung, C. H., \& Yeh, C. Y. (2012). When does investor sentiment predict stock returns? Journal of Empirical Finance, 19(2), 217-240.

Cochrane, J. H. (2005). Financial markets and the real economy. The

- National Bureau of Economic Research. Retrieved from http://www. nber.org/papers/w11193.

Cochrane, J. H. (2011). Understanding policy in the great recession: some unpleasant fiscal arithmetic. European Economic Review, 55, 2-30.

Daniel, K., Hirshleifer, D., \& Subrahmanyam, A. (1998). Investor psychology and security market under- and overreactions. Journal of Finance, 53, 1839-1886.

De Bondt, W., Muradoglu, G., \& Staikouras, S. K. (2008). Behavioral finance: quo vadis? Journal of Applied Finance, 19, 7-21.

DeStefan, M. (2004). Stock returns and the business cycle. The Financial Review, 39, 527-547.

Fernandes, C., Gama, P., \& Vieira, E. (2013). Does sentiment matter for stock market returns? Evidence from a small European market. Journal of Behavioral Finance, 14, 253-267.

Fisher, K., \& Statman, M. (2000). Investor sentiment and stock returns. Financial Analysts Journal, 56, 16-23.

Fisher, K., \& Statman, M. (2003). Consumer confidence and stock returns. The Journal of Portfolio Management, 30, 115-127.

Fuhrer, J.(1993). What role does consumer sentiment play in the U.S. macroeconomy? New England Economic Review, Jan, 32-44

Garcia, D. (2013). Sentiment during recessions. The Journal of Finance, LXVIII, 1267-1300.

Hansen, L. P., \& Jagannathan, R. (1997). Assessing specification errors in stochastic discount factor models. The Journal of Finance, 52(2), 557-590.

Hansen, L. P., \& Richard, S. F. (1987). The role of conditioning information in deducing testable restrictions implied by dynamic asset pricing models. Econometrica: Journal of the Econometric Society, 55, 587-613.
Hirshleifer, D. (2001). Investor psychology and asset pricing. Journal of Finance, 61, 1533-1597.

Jansen, W. J., \& Nahuis, N. J. (2003). The stock market and consumer confidence: European evidence. Economic Letters, 79, 89-98.

Kiyotaki, N., \& Moore, J. (1997). Credit cycles. Journal of Political Economy, 105(2), 211-248.

Kurov, A. (2010). Investor sentiment and the stock market's reaction to monetary policy, Journal of Banking and Finance, 34(1), 139-149.

Lopez-Salido, D., Stein, J. C., \& Zakraj `sek E. (2015). Credit-market. sentiment and the business cycle, unpublished manuscript. Retrieved from http://sčholar.harvard.edu/files/stein/files/credit_market_ sentiment_and_the_business_cycle_final.pdf.

Leger, L. A., \& Leone, V. (2007). Changes in the risk structure of stock returns. Consumer confidence and the dotcom bubble. Department of Economics, Loughborough University: Retrieved from https://. ideas.repec.org/p/lbo/lbowps/2007_15.html.

Lemmon, M., \& Portniaguina, E. (2006). Consumer confidence and assets prices: some empirical evidence. The Review of Financial Studies, 19, 1499-1528.

Malmendier, U., \& Geoffrey, T. (2005). Does overconfidence affect corporate investment? CEO overconfidence measures revisited. European Financial Management, 11, 649-659.

Mendicino, C., \& Punzi, M. T. (2013). Confiança e atividade económica: o caso de Portugal, Banco de Portugal. Boletim Económico, Inverno 43-53.

Mishkin, F. (2001). The economics of money, banking, and financial màrkets. The Addison-Wesley Series in Economics (6a. ed.). Mishawaka, IN: Prentice Hall.

Neal, R., \& Wheatley, S. (1998). Do measures of investor sentiment predict returns? The Journal of Financial and Quantitative Analysis, 33(4), 523-547.

Neves, E., Proença, C., \& Martins, P. (no prelo). Interdependence or reaction when the background is the financial crisis: the case of Portuguese stock market. International Journal of Economic Perspectives.

Oest, R., \& Franses, P. (2008). Measuring changes in consumer confidence. Journal of Economic Psychology, 29, 255-27.5.

Otoo, M. (1999). Consumer sentiment and the stock market. Finance and Economics Discussion Series. Board of Governors of the Federal Reserve System. North-Holland, Amsterdam: EconPapers..

Papavassiliou, V. G. (2014). Cross-asset contagion in times of stress. Journal of Economics and Business, 76, 133-139.

Schmeling, M. (2009). Investor sentiment and stock returns: some international evidence. Journal of Empirical Finance, 16, 394-408.

Serapio, S. J., Barbedo, H. C., \& Araújo, S. G. (2015). Is there herd effect on stocks with high liquidity of the Brazilian market? Journal of Financial Innovation 1(2), 77-90.

Shefrin, H. (2001). Behavioral corporate finance. Journal of Applied Corporate Finance, 14(3), 113-126.

Shefrin, H. (2005). Behavioral corporate finance. New York, NY: McGrawHill.

Shefrin, H. (2008). Risk and return in behavioral SDF based asset pricing models. Journal of Investment Management, 6, 1-19.

Shiller, R. (2005). Irrational exuberance (2a ed.), New.York, NY: Doubleday.

Shu, H. (2010). Investor mood and financial markets. Journal of Economic Behavior \& Organization, 76(2), 267-282.

Tetlock, P (2007). Giving content to investor sentiment: the role of media in the stock market. Journal of Finance, 62, 1139-1168.

Thaler, R. (1999). The end of behavioral finance. Financial Analysts Journal, 55, 12-17.

Wang, Y., Keswani, A., \& Taylor, S. J. (2006). The relationships between sentiment, returns, and volatility. International Journal of Forecasting, 22(1), 109-123.

Zouaoui, M., Nouyrigat, G, \& Beer F. (2011). How does investor sentiment affect stock market crisis? Evidence from panel data. The Financial Review, 46(4), 723-747. 
Correspondence address:

Maria Elisabete Duarte Neves

Instituto Superior de Contabilidade e Administração de Coimbra, Departamento de Finanças

Quinta Agrícola, Bencanta - 3040-316

Coimbra - Portugal

Email: mneves@iscac.pt

\section{ANNEXES}

Annex 1 Stationarity of the PSI-20 time series

Autocorrelation and Akaike

Augmented Dickey-Fuller Test Equation

\begin{tabular}{|c|c|c|c|c|}
\hline Variable & C & RT(-1) & & \\
\hline t-statistic & 0.25487 & -8.18235 & & \\
\hline Prob. & 0.79920 & 0.0000 & & \\
\hline Adjusted R-squared & 0.338295 & & S.D. dependent var & 0.056754 \\
\hline S.E. of regression & 0.046167 & & Akaike info criterion & -3.297854 \\
\hline Sum squared resid & 0.272814 & & Schwartz criterion & -3.253738 \\
\hline Log likelihood & 216.3605 & & Hannan-Quinnn criterion & -3.279928 \\
\hline F-statistic & 66.95087 & & Durbin-Watson stat & 1.973828 \\
\hline Prob (F-statistic) & 0.000000 & & & \\
\hline
\end{tabular}

Ljung-Box Test - Absence of Autocorrelation

\begin{tabular}{ccccc}
\hline Lag & AC & PAC & Q-Stat & Prob \\
\hline 6 & -0.035 & -0.121 & 26.240 & 0.000 \\
\hline 8 & -0.017 & -0.051 & 26.571 & 0.001 \\
\hline 10 & -0.043 & 0.000 & 26.982 & 0.003 \\
\hline 12 & -0.098 & -0.108 & 28.398 & 0.005 \\
\hline
\end{tabular}

Akaike

Dependent variable: RT

\begin{tabular}{|c|c|c|c|c|}
\hline Variable & C & $\operatorname{AR}(1)$ & & \\
\hline Coefficient & 0.001518 & 0.320181 & & \\
\hline Prob. & 0.79930 & 0.0002 & & \\
\hline t-Statistic & 0.254837 & 3.853716 & & \\
\hline Sample (adjusted): & \multicolumn{2}{|c|}{$2003 M 32013 M 4$} & & \\
\hline Included observations: & \multicolumn{2}{|c|}{103 after adjustments } & & \\
\hline R-squared & 0.103962 & & Mean dependent var & 0.001218 \\
\hline Adjusted R-squared & 0.096962 & & S.D. dependent var & 0.048582 \\
\hline S.E. of regression & 0.046167 & & Akaike info criterion & -3.297854 \\
\hline Sum squared resid & 0.272814 & & Schwartz criterion & -3.253738 \\
\hline Log likelihood & 216.3605 & & Hannan-Quinnn criterion & -3.279928 \\
\hline F-statistic & 14.85113 & & Durbin-Watson stat & 1.973828 \\
\hline Prob (F-statistic) & 0.000183 & & & \\
\hline
\end{tabular}




\begin{tabular}{cc}
\hline AR & AKAIKE \\
\hline 1 & -3.297854 \\
\hline 2 & -3.277438 \\
\hline 3 & -3.281873 \\
\hline 4 & -3.278402 \\
\hline 5 & -3.266479 \\
\hline 6 & -3.258284 \\
\hline 7 & -3.235320 \\
\hline 8 & -3.212935 \\
\hline
\end{tabular}

Annex 2 Stationarity of the Consumer Confidence Index time series Augmented Dickey-Fuller Test Equation

\begin{tabular}{|c|c|c|c|c|}
\hline Variable & C & LN_ICC(-1) & & \\
\hline t-Statistic & 0.12238 & -5.03970 & & \\
\hline Prob. & 0.90320 & 0.0000 & & \\
\hline R-squared & 0.382517 & & Mean dependent var & 0.005327 \\
\hline Adjusted R-squared & 0.367456 & & S.D. dependent var & 0.101224 \\
\hline S.E. of regression & 0.080506 & & Akaike info criterion & -2.155572 \\
\hline Sum squared resid & 0.265731 & & Schwartz criterion & -2.073656 \\
\hline Log likelihood & 48.34481 & & Hannan-Quinnn criterion & -2.125364 \\
\hline F-statistic & 25.39858 & & Durbin-Watson stat & 1.821260 \\
\hline Prob (F-statistic) & 0.000010 & & & \\
\hline
\end{tabular}

Akaike

Dependent variable: LN_ICC

\begin{tabular}{lccc}
\hline Variable & \multicolumn{1}{c}{ C } & AR(1) \\
\hline Coefficient & 0.001875 & 0.197203 & \\
\hline Prob. & 0.90340 & 0.2228 & \\
\hline & & & \\
\hline t-Statistic & 0.122157 & 1.237973 & \\
\hline Sample (adjusted): & 2003Q2 2013Q4 & Mean dependent var \\
\hline Included observations: & 43 after adjustments & S.D. dependent var \\
\hline & & Akaike info criterion & 0.000567 \\
\hline R-squared & 0.036033 & Schwartz criterion \\
\hline Adjusted R-squared & 0.012522 & Hannan-Quinnn criterion \\
\hline S.E. of regression & 0.080506 & Durbin-Watson stat \\
\hline Sum squared resid & 0.265731 & -2.155572 \\
\hline Log likelihood & 48.34481 & -2.073656 \\
\hline F-statistic & 1.532577 & 1.82126 \\
\hline Prob (F-statistic) & 0.222768 & \\
\hline
\end{tabular}




\begin{tabular}{cc}
\hline AR & AKAIKE \\
\hline 1 & -2.155557 \\
\hline 2 & -2.131529 \\
\hline 3 & -2.065491 \\
\hline 4 & -2.001288 \\
\hline 5 & -1.962983 \\
\hline 6 & -1.884350 \\
\hline 7 & -1.820096 \\
\hline 8 & -1.761570 \\
\hline
\end{tabular}

Annex 3 Granger Test

Pairwise Granger Casuality Tests (Lag 1)

\begin{tabular}{lccc}
\hline Null Hypothesis: & Obs & F-Statistic & Prob \\
\hline RET does not Granger Cause V_RES & 41 & 6.45089 & 0.0153 \\
\hline V_RES does not Granger Cause RET & & 0.08475 & 0.7725 \\
\hline
\end{tabular}

